the limit to which the eutectoid is broken up and therefore within the limit of high distortion. The inner boundary of the layer of recrystallized metal, for $400^{\circ}$ and $600^{\circ}$, is sharp and definite. At $800^{\circ}$ this is not so marked; in this case, in making the measurements, the maximum depth was chosen.

Figs. 4, 5, 6 and 7 show the appearance of this outer layer of recrystallization.

\section{SUMMARY OF RESULTS}

I-The metal, upon annealing, is first brought into "physico-chemical equilibrium." The dendritic structure persists until heated for approximately two hours at $800^{\circ}$. The absorption of the eutectoid depends much upon how the cast sample was cooled while solidifying; four hours' heating at $800^{\circ}$ is required for its disappearance in those samples which solidify very slowly.

II-No evidence was found suggesting a change of crystal size of cast samples which had not been distorted in any way.

III-Recrystallization, including "twinning," was found, only, to follow distortion; samples which were highly strained as a result of very sudden cooling from the molten state behave upon annealing the same as those mechanically distorted. Chill castings may be expected to behave in a similar manner.

IV-The progress of recrystallization upon annealing for different periods of time at the same temperature is in agreement with Tammann's theory of recrystallization.

$V$-Aside from the crystal size and the modification introduced by "twinning," the end condition of material annealed directly after casting and that annealed after a preliminary distortion of the crystalline structure is the same in the two cases (Figs. $\cdot 2$ and 7 ).

Bureac of STandards, Washington, D. C.

\section{EXPERIMENTS ON THE PRODUCTION OF GASOLINE FROM HYDROCARBON OILS OF HIGH BOILING POINTS}

By EARLE L. DAVIES

Received October 15, 1915

Gasoline is one of the materials used by the rubber industry in fairly large quantities, and, since it is used chiefly in cements, etc, which must be dried entirely free from any tarry matter, or similar oily or greasy matter, such ingredients, even in very small amounts, render it unsuitable for use. About the first of the year I9I3, when these experiments were made, the price of straight run gasoline was extremely high and, to us, the prospects for any reduction in price did not seem bright. The object of our work was, therefore, to find a feasible and profitable process for the production of a satisfactory supply of gasoline from some heavy fuel oil or similar cheap hydrocarbon oil.

In all of the samples of gasoline which we had examined, made by so-called "cracking" processes, a considerable amount of unsaturated hydrocarbons, tarry matter, etc., was present. It was, therefore, evident that our process must include some cheap and efficient hydrogenation feature, from which it followed that nascent hydrogen would be desirable. The well known method of producing hydrogen by passing steam over red-hot chips of iron or steel suggested. itself as being feasible. Some modification of this method has been the subject of various patents which it is not the purpose of the author to review in this paper.

Our problem, therefore, resolved itself into two parts:

I-A study of the best conditions for cracking the oil.

II-The determination of the most favorable conditions for saturating with hydrogen, those portions which were converted into unsaturated compounds.

In all of out work, except as otherwise noted, we used an oil obtained under the name of "Distillates" from the Factory Oil Co., of Akron (a marketing concern). Yields were determined by fractionating $200 \mathrm{cc}$. of the product condensed in the apparatus, through a three-bulb Le Bel-Henninger distilling tube and collecting that portion which came over below I $75^{\circ} \mathrm{C}$.; this temperature, which was arbitrary, represented a product averaging $60^{\circ}$ Bé.

Our apparatus for studying the problem of cracking consisted of an iron retort holding $\mathrm{I}^{1 / 2}$ liters, made by capping a piece of 4 -in. standard wrought-iron pipe. From this retort a piece of $\mathrm{I}$-in. (S. W. I.) pipe $40 \mathrm{in}$. long was passed through a 30 -in. combustion furnace to a condenser, made by coiling one $20-\mathrm{ft}$. length of I-in. (S. W. I.) pipe, at the outlet of which was placed a pressure gauge and finally a valve for regulating back pressure on the apparatus. The retort was heated with an ordinary laboratory gas blast lamp.

We first studied the effect of distilling the oil and condensing under pressure, substantially as described by Burton's patent. ${ }^{1}$ Experiments were made distilling under $10,25,50,75$ and 90 lbs. gatnge pressure; the furnace under the 4o-in. length of pipe was not lighted. Our highest yields gave only about 3 per cent naphtha, determined as above described; we attributed the low yields obtained as due to the fact that a relatively large portion of the oil had distilled over and condensed before the desired back pressure was obtained.

The next step was a study of the effect of superheating the vapors as they passed through the 4o-in. length of pipe. Unfortunately, in this series of experiments, we had no means of measuring the temperature of the vapors, but the tube was kept red-hot and was probably heated to about $600^{\circ}$ to $650^{\circ} \mathrm{C}$. Rates of distillation, superheat, etc., were kept as nearly constant as possible. The results of the series were as follows:

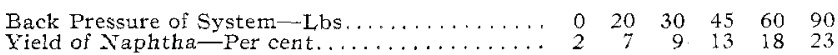

These experiments were repeated after filling the 40-in. tube with broken pieces of tile and brick. At 90 lbs. pressure we obtained a yield of 26.2 per cent, which was repeated twice.

The naphtha obtained in these experiments was 1 U. S. Pat. No. 1,049,667. 
slightly straw-colored; it possessed a distinct odor and was attacked more or less vigorously by cold, concentrated sulfuric acid, proving the presence of unsaturated hydrocarbons.

Thus far we had succeeded in showing:

I-That pressure is essential.

2-That a combination of pressure and superheat is desirable.

3-That a refractory material in the superheated portion is desirable.

4--That carbonization, to a certain extent, takes place in the retort.

5-That the naphtha did contain unsaturated hydrocarbons.

This gave us sufficient data to start on the second main problem of our work, that of hydrogenating the unsaturated products. Mention has already been made of our intention to obtain nascent hydrogen by means of the action of steam on iron chips. This, it seemed, might easily be done in the chamber in which the oil vapors were superheated and so much of the cracking took place. The iron chips would have the advantage of acting as a refractory material to ture measured at $D_{2}$ were mixed with the superheated steam in the Tee $H$, the mixture then passing on through the cracking and hydrogenating chamber $K$ and out at a temperature indicated at $D_{3}$, into the condenser $L$; the temperature of the condensate was indicated at $D_{4}$ and back pressure, indicated at $G_{4}$, on the apparatus, was regulated by valve $M$. The condensate was collected in $N$ where the condensed excess steam separated from the oily condensate, and was drawn off at the bottom, while the gases after bubbling through the condensate, escaped at the top through the trap $O$ and meter $P$ at a pressure of Io in. of water, maintained by bubbling through that depth of water.

The details of the process were as follows:

Steam was obtained from the Power Plant, about one-quarter mile away; its quality probably was not much above 90 per cent dry steam. A Type T-B-2 General Electric Co. steam flow meter was used. Fig. II shows a cross section of the superheater $C$, which consisted of 55 to $60 \mathrm{ft}$. of $5 / 32$ in. Wall by $\mathrm{I}^{1 / 4}$

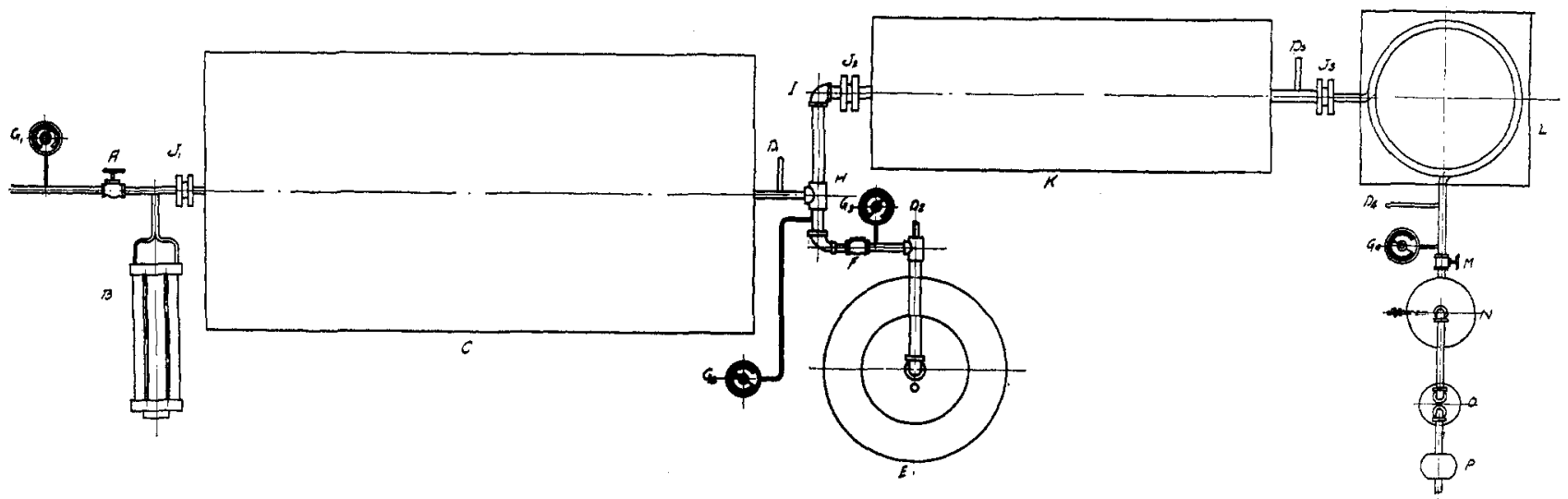

A-Valve
B-Steam Flow Meter
C-Superheater
$D_{1} D_{2} D_{3} D_{4}-$ Well for Pyromete
E-Retort Valve
F-Check Valve hydrogen would be present to act upon the unsatura ted products at the moment of their formation. In connection with the action of steam on iron it is well to bear in mind the analogous reaction in the mantfacture of water gas, ${ }^{1}$ viz.:

$$
\mathrm{C}+{ }_{2} \mathrm{H}_{2} \mathrm{O}=\mathrm{CO}_{2}+{ }_{4} \mathrm{H} \text { at about } 600^{\circ} \mathrm{C} \text {., }
$$

while the reaction becomes

$$
\mathrm{C}+\mathrm{H}_{2} \mathrm{O}=\mathrm{CO}+2 \mathrm{H} \text { at about } 1000^{\circ} \mathrm{C} \text {. }
$$

from which we may venture that best results are probably obtained at temperatures. which are not too high.

For the succeeding work, we built the experimental plant shown diagrammatically in Fig. I. Steam at the pressure indicated by $G_{1}$ was admitted through the valve $A$ at a rate indicated by steam flow meter $B$ and passed through the superheater $C$ into the Tee $H$ at a temperature measured at $D_{1}$ and pressure indicated by $G_{2}$. Oil was distilled from the retort $E$ at a pressure indicated by $G_{3}$. The vapors at a tempera-

1 Thorpe's Dict. App. Chem., Vol. II. p. 706.

\section{K-Cracking Chamber I-Condenser M-Valve for Regulating Back Pressure N-Apparatus for Collecting Condensate and Separating Condensed Steam O-Trap for Separating Liquid from Gases Formed $\mathrm{P}-$ Meter for Measuring Gases Formed}

in. O. D. "Shelby" cold-drawn seamless steel mechanical tubing bent into a trough-shaped coil of $5^{1 / 2}$ turns, the top coil of which was about 20 in. $x$ 60 in., all joints being electrically welded. The tubing steel, containing from $0.7_{7}$ to 0.20 per cent carbon, seemed to withstand excellently the severe conditions imposed; a scale of oxide appeared to form both outside and inside the tube, which, if undisturbed, prevented further rapid corrosion. Crane's malleable iron pipe fittings for I.500 lbs. pressure were used throughout. 'Temperatures were measured by Hoskins' base metal thermocouples connected to one meter by means of one of their four-point selective switches. The retort was made by drilling a Io-in, hole in a piece of I 2 -in. shafting and welding on a collar for bolting and sealing the top. The cracking chamber consisted of one piece of "Shelby" seamless steel mechanical tubing $2^{3} / 8^{-i n}$. O. D., $1 / 16^{-i n}$. wall by 7 ft. long enclosed in a furnace with 4 -in. wall built of fire brick, and heated by natural gas; this tube was filled with iron and steel shavings. The gas burners used for superheater and "Cracker" are shown in detail in Figs. III and IV: this 
construction gave equal distribution of the flame throughout the entire length of the burner.

In conducting the experimental work, the following factors were to be studied:

I-Confirmation of our previous opinions as to the desirability of pressure.

2-Rate of flow of steam as compared to the amount of oil.

3-Temperature of the steam entering the Tee $H$.

4-Final temperature of the mixed vapors at $D_{3}$.

5 -The rate of distillation of the oil.

6 -The construction of the cracking chamber.

7 -The nature of the catalyzer used.

The first series of experiments made with this apparatus was to study the influence of pressure. The type of burner shown in Fig. III, having an órdinary air mixer, was used, but with it we could not get anything like the desired temperatures (we had no pyrometer at this time); the pressire at $G_{2}$ and $G_{3}$ was maintained at a point which gave an average flow of steam of about roo lbs. per hour; all other factors were kept as nearly constant as possible. The results were as follows:

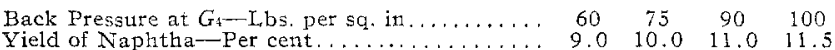

Although these results are low as compared with our previous experiments without steam, the same ments such an instrument was installed. The results obtained are given in Table $I$.

\begin{tabular}{|c|c|c|c|c|c|c|}
\hline \multirow[b]{2}{*}{$\begin{array}{l}\text { Rate of } \\
\text { distillation } \\
\text { for } 1 \text { gal. }\end{array}$} & \multirow[b]{2}{*}{$\begin{array}{l}\text { Av. temp. } \\
\text { steam } \\
\text { at } D_{l}\end{array}$} & \multicolumn{2}{|l|}{ TABLE I } & \multicolumn{3}{|c|}{ YIELD OF } \\
\hline & & $\begin{array}{l}\text { Av. temp. } \\
\text { mixed vapors } \\
\text { at } D_{3}\end{array}$ & $\begin{array}{l}\text { Sp. gr. } \\
\text { of con- } \\
\text { densate }\end{array}$ & $\begin{array}{l}\text { Loss } \\
\text { Pet } \\
\text { cent }\end{array}$ & $\begin{array}{l}\text { THA } \\
\text { Per } \\
\text { cent }\end{array}$ & $\begin{array}{c}\text { FORMED } \\
\text { CH. } \\
\mathrm{ft} .\end{array}$ \\
\hline & $\begin{array}{l}\text { Without } \\
\text { pyrometer }\end{array}$ & (Bright red & $\ldots$ & $\begin{array}{l}15 \\
12 \\
14\end{array}$ & $\begin{array}{l}34.0 \\
29.5 \\
34.0\end{array}$ & \\
\hline $\begin{array}{l}20 \text { min. } \\
30 \text { min. } \\
15 \text { min. } \\
18 \text { min. } \\
25 \text { min. } \\
15 \text { min. }\end{array}$ & $\begin{array}{l}585^{\circ} \mathrm{C} \text {. } \\
560 \\
605 \\
480 \\
490 \\
525\end{array}$ & $\begin{array}{l}\text { Red } \\
645^{\circ} \mathrm{C} . \\
635 \\
635 \\
635 \\
640 \\
600\end{array}$ & $\begin{array}{l}41^{\circ} \text { 'ं Bé. } \\
38 \\
38 \\
37 \\
38 \\
36\end{array}$ & $\begin{array}{r}17 \\
13 \\
15 \\
18 \\
12 \\
12 \\
12 \\
4\end{array}$ & $\begin{array}{l}34.5 \\
34.2 \\
30.5 \\
25.0 \\
22.0 \\
22.0 \\
18.0\end{array}$ & $\begin{array}{l}21 \\
20 \\
21 \\
30 \\
26.1 \\
15.0 \\
17.5 \\
12.2\end{array}$ \\
\hline
\end{tabular}

These results indicate that the steam should be heated to about $600^{\circ} \mathrm{C}$. before mixing with the oil vapors, which must in turn be distilled so as to pass through the cracking chamber at the proper rate, which would in all probability depend upon the length of the cracking period.

We next wished to determine the effect of increasing the length of the cracking chamber upon the rate at which the oil could be fed into the apparatus, thereby obtaining data which would enable us to design a commercial plant; moreover with the flanes hitting the tube only once, then going up the chimney, we were losing a vast ammunt of heat which was being measured in terms of gas supplied to the furnace as

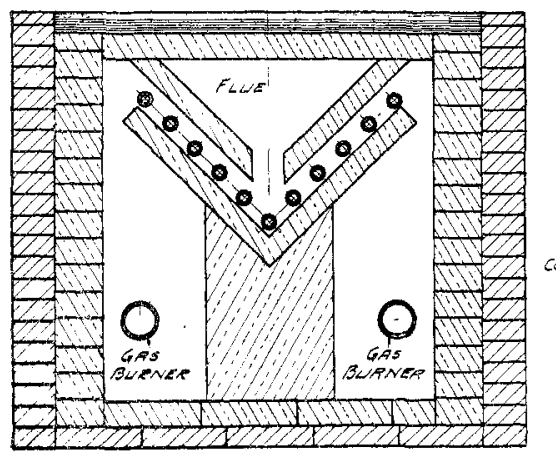

FIG. II-STEAM SUPERHEATER

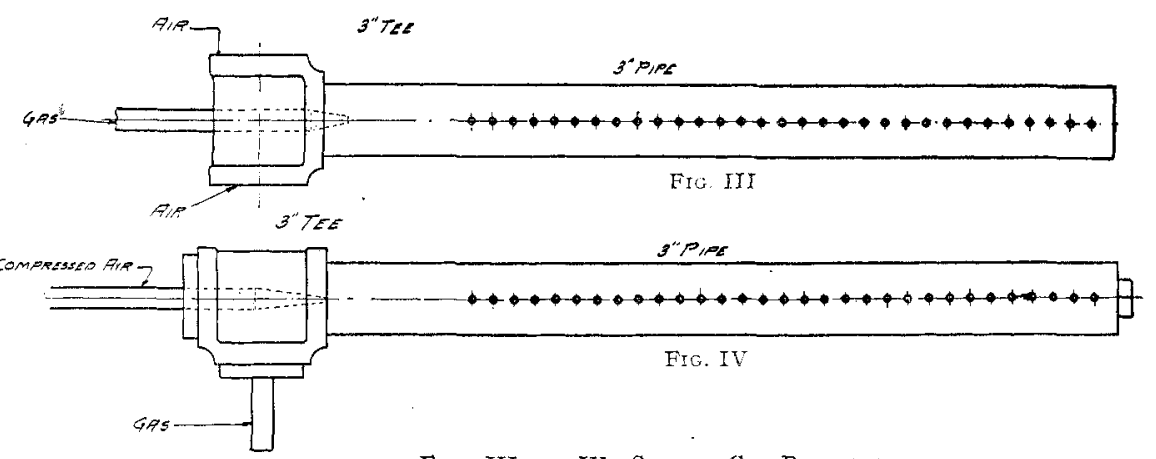

Figs. III anp IV-Spectal Gas Burners tendency to increase with pressure is evident, the low yields being caused by low temperatures. We think, therefore, that it has been conclusively demonstrated that pressure is essential. It would have been interesting to have studied the effect of pressures higher than roo lbs., but for our work we were limited to ro5 lbs. pressure on the steam line; we did not think it worth while to make provisions for higher prešsures inasmuch as difficulties would be encountered in the safe operation of a commercial plant under greater pressure at the high temperatures in use.

After the just mentioned series of experiments, the burners were all fitted with compressed air mixers as shown in Fig. VI; these burners gave excellent results.

We now performed a few experiments to determine the best rate of flow for the steam. The best results, judging from the appearance of the product, were obtained with pressure at $G_{2}$ about I00-105 lbs. and the pressure at $G_{4}$ about $901 \mathrm{bs}$., which gave us about Io lbs. of steam per gallon of oil. In all subsequent work, the steam was regulated accordingly.

Our work had been carried on without a pyrometer up to this point, but during this series of experi- fuel. The "cracking" chamber was therefore changed to the construction shown in Figs. $V$ and VI: $2^{\frac{3}{3}} 8^{-i n}$. O. D. by $1 / 10^{-i n}$ wall, $3-4$ per cent nickel steel seamless mechanical tubing was used; unions were provided after each passage through the furnace in order to permit the introduction of the refractory catalyzer and the frequent renewal of the same.

The series of experiments recorded in Table II was intended as a check upon the indications of Table I, under the just mentioned changed conditions, but does not present a clearly defined series of experiments with only one factor varied at a time, and for various rea sons was not carried to a conclusion.

Chips and shavings of iron and steel were used as a catalyzer in the tubes of the cracking chamber. For the best results they should be renewed rather fre. quently, since a scale of oxide forms on the outside which renders them less active. We performed a few experiments with about 5 lbs. of nickel chips and nickel wire gauze mixed with the iron shavings. After about a week, most of the nickel had disappeared nor could we see any marked improvement in the product while using the nickel. 
That we were able to produce hydrogen was shown by running steam alone (no oil) through the apparatus, thereby obtaining a gas at the rate of about 5 feet per hour, which analysis showed to be nearly pure hydrogen.

Several experiments were made, using, in place of the new oil, residues from which the naphtha formed in previous runs had been distilled with similar conditions; the net yield was about the same. We also tried placing the condensate recovered in $N$ back in the retort before distilling off the naphtha, and found that gas was not formed faster than could be attrib- small amounts as 2 gallons in so large an apparatus, it would be easy to lose quite a considerable percentage. We see no reason why the loss could not be kept under to per cent in operating a plant on a commercial scale.

The naphtha obtained by our process differs very little in appearance from commercial naphtha; it is very nearly water-white and has very little unnatural odor; it is decidedly superior to the samples of commercial "cracked" naphtha which we have examined. Upon treating our product with sulfuric acid, it was acted upon less than any commercial "cracked" naphtha
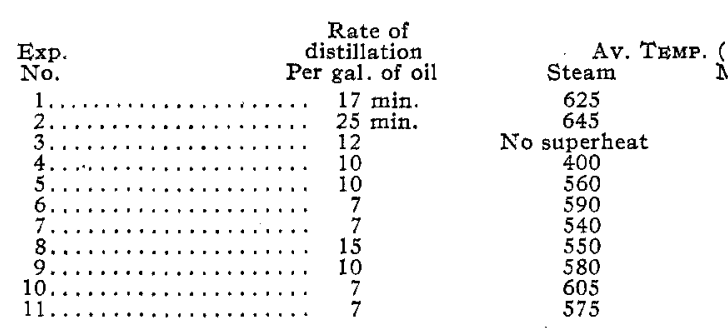

uted to the action of the steam on the iron until the temperature at $D_{2}$ of the oil vapors was over $300^{\circ}$ C., showing that the lighter portions were broken down further only with great difficulty.

A few experiments were made upon a very viscous and dirty Ohio crude oil, having a specific gravity $36^{\circ} \mathrm{B}$; it yielded 27 per cent by fractionation and collecting that portion which came over below $175^{\circ} \mathrm{C}$., it contained about 2 per cent moisture. We ran this oil through the process without previously distilling off the naphtha which it contained. Assuming that

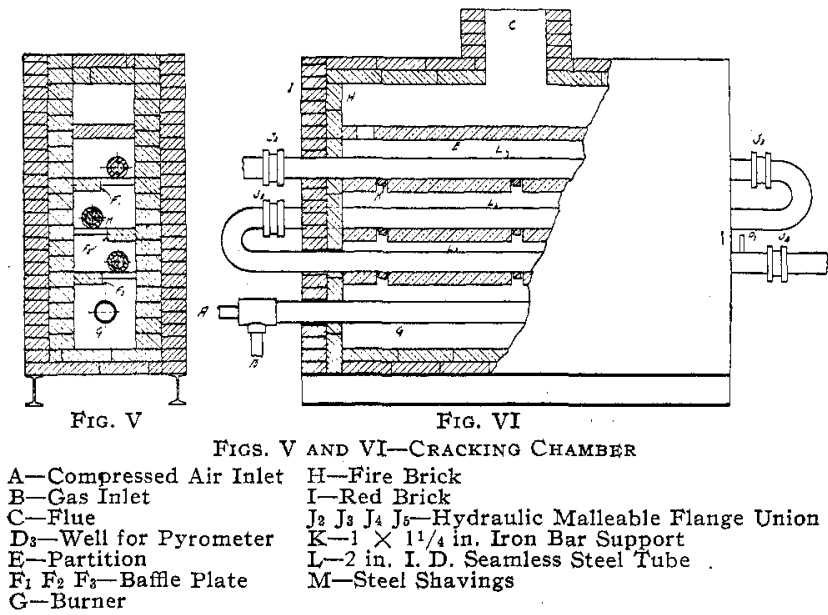

none of this naphtha was broken up into gas and that the remaining 73 per cent produced 34 per cent of naphtha in the process, we would expect a total yield of 5 I. 8 per cent; as a matter of fact, the total yield of naphtha obtained was 54.5 per cent. The loss due to the formation of gas was high. The residues, after the naphtha had been distilled, was as good, for future use, as the fresh "Distillates" (Paragraph 4).

The greatest item of expense in the process seems to be in the amount of oil lost through carbonization, gas formation, etc. When we obtained the best net results, this loss, in our experimental plant, averaged from ro to I 2 per cent. When starting with such
TABLE II

$\begin{array}{cccc}\begin{array}{c}\text { Sp.gr. of } \\ \text { condensate }\end{array} & \begin{array}{c}\text { Loss } \\ \text { Per cent }\end{array} & \begin{array}{c}\text { YIELD OF } \\ \text { NAPHTHA } \\ \text { Per cent }\end{array} & \begin{array}{c}\text { GAS } \\ \text { FORMED } \\ \text { Cu. ft. }\end{array} \\ 34.0^{\circ} \text { Be. } & 20 & 38.0 & 63.2 \\ 38.0 & 50 & 38.5 & 115.4 \\ 35.5 & 5 & 18.0 & 20.0 \\ 36.0 & 10 & 26.0 & 36.4 \\ 35.5 & 8 & 25.5 & 25.0 \\ 39.0 & 35 & 33.0 & 74.0 \\ 34.0 & 18 & 26.5 & 55.0 \\ 37.0 & 15 & 26.0 & 23.6 \\ 36.0 & 20 & 30.0 & 39.3 \\ 34.5 & 10 & 24.0 & 59.2 \\ 36.0 & 15 & 30.0 & 56.2\end{array}$

which we have seen, in spite of the fact that it had not been subjected to any of the usual washing treatments, our purification having been limited entirely to distillation. Several gallons were tried in motorcycle and automobile motors; in these tests there was no apparent difference between our naphtha and commercial $72^{\circ}$ naphtha; we looked especially for such troubles as carbonization, but could find no evidence of them.

\section{COST OF NAPHTHA PRODUCED}

The cost of naphtha produced by this process may be estimated as follows: Our experiments show that the entire apparatus could be maintained at the proper temperature, and the oil distilled, by the use of 30 cu. ft. of natural gas as fuel, per gallon of raw oil; natural gas if computed at its equivalent in coal is not worth more than 7 cents per I000 cu. ft. It must be remembered that our furnaces were designed with the view to easy manipulation rather than economy of fuel; in a commercial plant, the whole thing could be enclosed in one furnace and waste heat from the superheater used to heat the cracking chamber and to vaporize the oil. The product could be separated by fractional condensation in a dephlegmator without the use of additional heat. Thirty pounds of steam, and very probably much less, would be amply sufficient. Steam may be produced for 6 cents per I, $000 \mathrm{lbs}$.

One gallon of naphtha could be produced from $3^{1 / 3}$ gallons of raw oil, leaving the residue, minus about Io per cent loss, worth as much as before. The cost would therefore be: $\begin{aligned} \text { One gallon raw oil (converted) } \ldots \ldots \ldots \ldots \ldots \ldots & =x \text { cents } \\ 10 \text { per cent of } 311 / 3 \text { gals. oil lost at } x \mathrm{per} \text { gal... } & =x / 3 \text { cents } \\ 100 \text { feet of gas at } 7 \mathrm{c} \text { per } 1000 \ldots \ldots \ldots \ldots \ldots \ldots & =0.007 \text { cent } \\ 30 \text { bs. of steam at } 6 \mathrm{c} \text { per } 1000 \ldots \ldots \ldots \ldots \ldots & =0.002 \text { cent }\end{aligned}$

Which may be expressed in the form of the equation

$$
C=1.33 X+.0 .9
$$

where

$C=$ cost of naphtha obtained in cents per gal.

$X=$ cost of raw oil in cents per gallon. 


\section{SUMMARY}

These experiments have established the following facts:

I-That a satisfactory naphtha may be obtained by means of this process wherein the oil is cracked in the presence of nascent hydrogen.

2-That superheating the oil vapors is desirable for "cracking."

3-That pressure is necessary for "cracking."

4-That a combination of pressure and superheat is essential.

5-That the presence of a refractory material in the "cracking chamber" acts as a catalyzer, aids the "cracking," and increases the yield of naphtha obtained.

6-That hydrogen is formed in the manner described, and that it evidently does unite with a greater portion of the unsaturated decomposition products formed, producing saturated compounds.

7 -That iron or steel shavings in the cracking chamber constitute a satisfactory catalyzer.

8 -That the catalyzer should be frequently renewed.

9-That the yields of naphtha obtained increase as the pressure is increased up to Ioo lbs.; above that pressure we have no data.

ro-The best results were obtained when using about Io lbs. of steam per gallon of oil.

I I-That the steam should be superheated to at least $600^{\circ} \mathrm{C}$. before mixing with the oil vapors.

I 2-That the mixture of superheated steam and oil vapors should be heated to $650^{\circ}$ to $675^{\circ}$ in the "cracking chamber."

I3-That the residue, obtained by distilling off the naphtha formed, is worth just as much as the original "raw" oil.

I4-That carbonization takes place in the retort and more or less gas is formed in the process.

I 5 -Oils having higher boiling points are "cracked" easier than those having lower boiling points, but the quantity of gas formed is greater.

I6--That the cost of naphtha produced by this process may be approximately expressed by the equation

where

$$
C=\mathrm{I} .33 x+0.9 \text {, }
$$

$C=$ the cost of the naphtha in cents per gallon,

$X=$ the cost of the starting oil in cents per gallon.

As to future work on the problem, we have considered the following:

I-More careful study of the temperature to which the steam should be superheated before mixing with the oil. This might lead, in the construction of a commercial plant, to placing the steam superheater next to the fire and utilizing the heat for cracking, after it leaves this superheater.

II-A study of spraying the cold oil into the superheated steam in a mixing and vaporizing chamber, which later might or might not have to be heated.

III-A more careful study of the construction of the cracking chamber, and the method of passing the vapors through the same, with the idea of determining whether it is not better to heat the vapors to the desired temperature as quickly as possible.
In conclusion, the writer desires to express his thanks to Mr. W. W. Sanders and to Mr. L. M. Bourne, under whose supervision these experiments were performed, for their interest and suggestions.

Chemical, Iaboratory of the Goodyear Tire \& Rubber Company AxRON, OHIO

\section{REFINING VEGETABLE OILS ${ }^{1}$}

By Charles BaskerviLLE

Crude vegetable and animal oils contain a variety of impurities traceable to a great variety of causes. The character of the crude oil depends not only upon the kind and part of the vegetable (wood, nut, seed, etc.) or animal (fish, whale, etc.) used, but the quality of the raw material at the time of expressage or extraction (rusting, rotting, fermentation, sprouting, heating, etc.), the method followed, the care exercised in the process, and the conditions to which the oil is subjected prior to its refining. It is not proposed to discuss these matters in detail, as this communication deals more specifically with certain of the vegetable oils.

A distinguished oil chemist in a recent interesting summary of the "Contributions of the Chemist to the Cottonseed Oil Industry,", has said, "the chemist

* * * found that the quality of the oil closely followed the free fatty acid present" 3 and "The chemist's greatest service to the industry has been in the refining of the oil, $* * * *$ and finally bringing into use the tintometer for measuring the color against standard glasses * * * * $\quad$ * "4

The present customary practice for refining vegetable oils referred to depends upon neutralizing the free fatty acids in the crude oil, usually by agitating the oil with an aqueous solution of an alkali, the strength and the amount having been previously determined by laboratory tests, agreed upon as a standard, and then heating the mixture during agitation to a suitable temperature until the oil "breaks." The mass is then allowed to stand until the "foots" settle to the bottom of the kettle, when the supernatant oil is drawn off by means of a swivel siphon. Invariably some "dreg" floats on top of the oil. If this be very great, its settling is sometimes facilitated by throwing salt on top of the oil in the kettle. In any event, the oil drawn off is clouded, perhaps on account of the presence of some dissolved soap, globulated moisture and suspended matter, doubtless colloidal in nature. This oil is then "brightened" after drawing off, by throwing in small amounts of fuller's earth, heating again, and passing through a filter press.

The time-factor in settling ( 6 to I 2 hours) of the "foots" materially affects the completeness of the separation referred to above, but in any event the "foots" is wet with oil. The "foots" also entrains oil. Consequently, during the rush season, the effi-

1 Read before the New York Section, American Chemical Society, April 9, 1915, and the Inter-State Cottonseed Crushers' Association, Birmingham, Ala., May 18, 1915. Since brought up-to-date, Jan., 1916.

2 Wesson, THus JotrnaL, $7(1915), 277$.

3 I have determined that this is true only in a general way, as was no doubt meant by the writer quoted.

1 One familiar with the color changes in glass may question the real accuracy attainable in the use of such standards. However, it is the best now available. 